\title{
Applying Social Science to Assess Public Interaction with Shale Gas
}

\author{
Matthew M. Strobl, Brian G. Southwell, Jason S. Norman, \\ Lauren A. McCormack, and Paul Pulliam
}

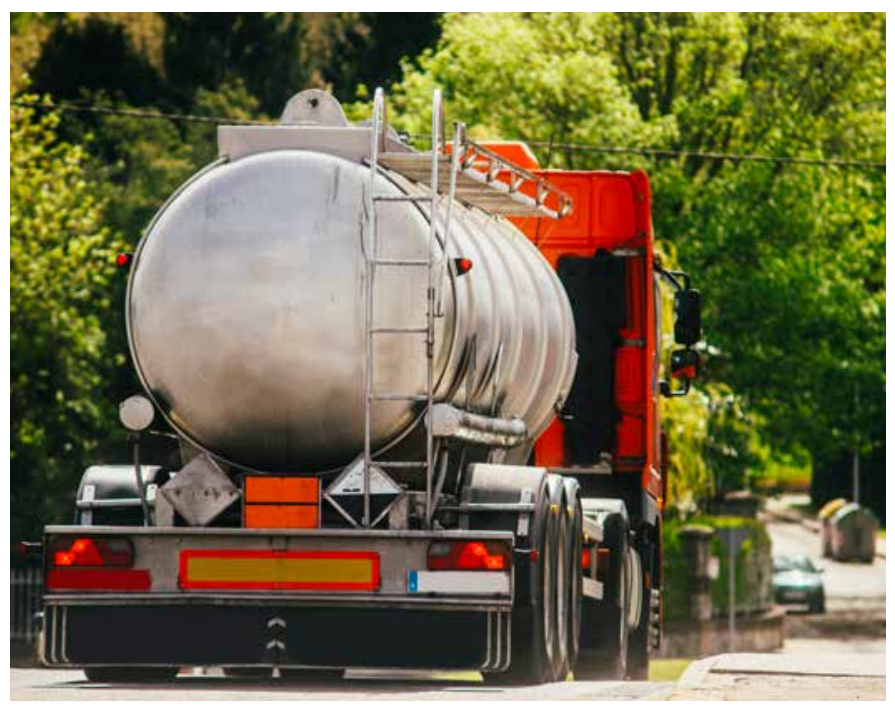

An increased understanding of the public's knowledge, attitudes, and behaviors about shale gas will help to clarify options for public policy and may identify other energyrelated public perception issues requiring study. An example of a possible research direction we consider in this brief is the extent to which the public has grasped a link between the use of shale gas and the resulting personal environmental and economic costs or benefits. We discuss theoretical considerations that can inform a research agenda, including constructs from psychological and behavioral theory. We also discuss next steps aimed at developing a research agenda that can help provide statistically reliable estimates and in-depth context of knowledge, attitudes, and behaviors related to shale gas. Finally, we identify four priorities as the field moves forward: transparency, evidence-based decision making, clear communication, and civic engagement.

\section{Shale Gas Explained}

- What it is. Natural gas formed from the decomposition of organic matter that, over millions of years, is exposed to high temperatures and pressures beneath the Earth's surface.

- Where it is found. Shale gas is found within shale formations developed when minerals combine with organic material.

- Why it matters. The low permeability of the shale prevents the gas from migrating out of the formation and collecting in traditional gas reservoirs. Modern drilling and fracturing techniques now allow the extraction of gas from these shale deposits; technically recoverable shale gas resources are estimated at more than 7 trillion cubic feet. ${ }^{1}$

- How we get it. Shale formations are generally horizontal, making conventional vertical drilling less effective. Modern drilling methods allow for horizontal drilling along the shale seam. Once drilled, the well is typically encased. The shale seam is perforated and then flooded with high-pressure hydraulic fracturing (fracking) fluid of approximately 95 percent water, 4.5 percent proppant particles, and 0.5 percent chemical additives. The proppant particles keep any fractures within the shale from closing, thereby allowing gas to flow from the formation. Once fractured, the well is cleaned out and production tubing inserted to allow gas recovery at the wellhead.

- What it means. The ability to extract shale gas has increased global gas resources by nearly a third, with many shale gas deposits located in North America. This is crucial for the US energy industry and for global energy considerations. 


\section{Shale Gas Overview}

The energy sector continually faces challenges related to affordability, environmental impact, and security of supply. New sources of inexpensive, abundant shale gas and oil are forcing the energy industry to reconsider the overall energy mix in the United States. The US Energy Information Administration, part of the Department of Energy, projects that shale gas will be the principal source of natural gas production over the next 25 years, eventually outstripping all other production sources combined. However, this shift carries risks: the newfound availability of extractable shale gas in North America and the associated, unconventional production techniques are driving new discussion about the environmental and societal impact created by these new resources.

Shale gas is a potential disruptor to the energy industry and associated sectors because of its relative abundance and low cost. Although it continues to require significant investment, shale gas energy production is making a major contribution to future energy security, foreign policy formulation, and the US trade balance, in addition to driving down the consumer cost of natural gas. Furthermore, natural gas combustion liberates the least amount of carbon dioxide $\left(\mathrm{CO}_{2}\right)$ of any fossil fuel: as one example, its $\mathrm{CO}_{2}$ emissions are 40 percent lower than those from combusting bituminous coal. By upgrading coal-burning facilities to use natural gas, US $\mathrm{CO}_{2}$ emissions dropped by approximately 430 million metric tons from 2008 to $2013 .^{2}$

Hydraulic fracturing (fracking), the process of drilling and injecting pressurized fluid into the ground in order to fracture shale and release contained natural gas, remains a hotly contested issue. Flowback fluid, the dust from proppant particles, chemicals used in the fracturing process, and uncaptured hydrocarbons may migrate to surrounding areas. Methane, the main component of shale gas, has a global warming potential (GWP100) around 28 times that of $\mathrm{CO}_{2},{ }^{3}$ meaning that any release of shale gas to the atmosphere has a greater greenhouse effect than the $\mathrm{CO}_{2}$ that would have been generated from burning it. The deep disposal of fracking-related wastewater has also been tied to significant increases in seismic activity. ${ }^{4}$ Finally, shale gas development requires costly updates to infrastructure.

\section{Public Understanding and Perceptions Related to Shale Gas}

Future policy on shale gas discovery, development, and regulation will benefit from behavioral science and public opinion research. Such a stance, in fact, is consistent with the executive order issued by the White House in September 2015 in direct support of applying behavioral science to policy issues. $^{5}$
Public understanding of (1) shale gas and oil as an energy source and (2) the process of hydraulic fracturing that has enabled extraction in recent years is vital for inquiry. Such understanding could facilitate or hamper public policy, commercial development, and consumer demand. Yet we know that public conception of energy is often outdated, inaccurate, or limited. ${ }^{6-10}$ Moreover, public opinion regarding policy concerns in the United States tends to be fluid and to evolve over time. ${ }^{11,12}$ Present public understanding does not necessarily forecast what public understanding will be in a decade.

Researchers should embrace a longitudinal perspective and remain open to the possibility that any single study may offer us only a snapshot of an evolving public mindset. For example, Boudet and colleagues found that the majority of people they interviewed had heard little or nothing about hydraulic fracturing and did not report having a firm stance for or against the practice. ${ }^{13}$ The extent to which people actually comprehend the mechanics of fracturing and the possible roles for shale gas in the world economy also remain empirical questions, as Rao notes. ${ }^{14}$

At least four dimensions of potential social science research related to shale gas are relevant to forecasting citizen and policymaker decision-making and to shaping public policy:

1. Description of who believes what regarding shale gas as an energy source

2. Studies of how shale gas has been depicted in prominent information environments

3. Research on the extent to which social movements against or for shale gas have developed or will develop over time

4. Work to understand the extent to which key actors in shale gas development and policy enjoy public perceptions of trust and credibility

Recent peer-reviewed papers on shale oil and gas production perceptions-for example, Boudet et al. ${ }^{13}$ and Theodori et al. ${ }^{15}$ - suggests prevalent uncertainty among laypersons, although Raimi and Leary ${ }^{16}$ point to some instances of entrenched and extreme views. Many respondents have acknowledged the potential benefits of hydraulic fracturing, yet most also favor regulation to ensure that health and environmental concerns are addressed. ${ }^{17-19}$ Krupnick and Siikamaki found general willingness to pay to mitigate risks associated with surface water harms among residents in Pennsylvania and Texas, but they also found relatively little support for paying to mitigate increased truck traffic and road congestion associated with shale gas development. ${ }^{20}$ 
A key caveat about perceived benefits and harms involves the limits of conventional survey measurement. Many large-scale surveys using close-ended questions regarding concerns measure only the specific responses included in the questionnaire and conceivably could miss additional considerations that are not specifically prompted. Work by Israel et al. to elicit concerns from an Internet-based convenience sample of residents from 24 US states is notable in this vein; respondents collectively articulated a wide range of potential consequences of shale gas development. ${ }^{21}$ Beyond simple agreement or disagreement measures that tap into public support for shale oil or gas extraction, then, an additional productive line of inquiry could be detailed elicitation and description of people's mental models of shale gas, or the sets of cognitive associations that people hold as they imagine and conceptualize the issue, following work on mental models and social representations. ${ }^{22-25}$

The literature on predictors of support for shale gas development is nascent, which is not surprising given relatively low public awareness to date. Political ideology and geographic proximity to drilling sites are often cited as predictors of attitudes toward energy development, as are vested economic interests. ${ }^{26,27}$ These interests can be direct, such as royalty payments, subsidized or reduced heating and cooling costs, and so on, or indirect, such as the general value of increased local employment. However, scholars have increasingly recognized the importance of interactions between political mindset and issue framing. Clarke et al.,28 for example, found that people generally responded more favorably to the notion of "shale oil or gas development" than to "fracking" regardless of reported political ideology. We need more research on demographic and ideological predictors as well as on the impact of various characteristics of messages.

News coverage of emerging issues can be inconsistent and driven by available sources. ${ }^{29}$ There has been relatively little empirical evidence regarding news coverage of shale oil and gas or its potential effects, however. Holloway and Rudd found that the majority of print, broadcast, and online news coverage on hydraulic fracturing in the Barnett, Haynesville, and Marcellus shale areas before 2013 negatively framed risks and lacked direct reference to scientific research. ${ }^{30}$ Evensen and colleagues found that most 2007 to 2011 newspaper coverage focused on potential water quality effects. ${ }^{31}$ We need more research on shale gas mentions in popular discourse, both in widely popular news outlets and in social media content.

Some papers on the effects of shale gas information exposure have appeared recently, such as Burger et al., ${ }^{32}$ Mazur, ${ }^{33}$ and Shen et al. ${ }^{34}$; much of that work suggests that salient mentions of a topic and the framing of news articles can impact information seeking and beliefs. Related new research on public engagement with technology has developed around the idea of "mobilized publics." 35 Understanding how movements or organized opposition efforts come into being also is relevant, as it might offer a role for sociology in understanding how advocacy efforts can shape public debate and discourse regarding shale gas and oil.

Trust in an information source matters when people make judgments about risks and benefits associated with a technology. ${ }^{36,37}$ Trust also predicts cooperation or compliance with recommendations. ${ }^{38}$ Because of the economic interests involved in shale gas and oil development, perceptions of trust are highly relevant. We are still learning how the general US population and populations in areas directly affected by extraction view the credibility of various relevant actors with regard to shale gas development. We do have some limited evidence of credibility concerns among citizens, however, regarding commercial organizations and government. ${ }^{21,39,40}$ Further work investigating the extent to which various actors enjoy widespread reputations of competency, caring, or objectivity would likely be productive.

\section{Summary and Next Steps}

Because shale gas presents both important opportunities and significant challenges, it is critical that current and future policy development be data- and evidence-driven. Data required are not limited to environmental science or economic topics. Researchers and policymakers should consider not only extraction and development research but also social science studies that investigate related costs, benefits, and public understanding of both. Information on public understanding of shale gas and oil will be important in forecasting citizen and policymaker decision-making, acceptance, and protest, for example. The availability of shale gas and oil holds tremendous possibility for the energy sector, but effective policymaking and business implementation will require an understanding of what is being said about this energy source and what people believe about it.

\section{References}

1. Energy Information Administration. EIA/ARI world shale gas and shale oil resource assessment. Arlington, VA: Advanced Resources International; 2013.

2. US Environmental Protection Agency. US greenhouse gas inventory report 1990-2013 (EPA 430-R-15-004). Washington, DC: National Service Center for Environmental Publications; 2015.

3. Edenhofer O, Pichs-Madruga R, Sokona Y, et al., editors. Climate change 2014: mitigation of climate change. Contribution of Working Group III to the fifth assessment report of the Intergovernmental Panel on Climate Change. Cambridge, UK: Cambridge University Press; 2014.

4. Sovacool BK. Cornucopia or curse? Reviewing the costs and benefits of shale gas hydraulic fracturing (fracking). Renew Sust Energ Rev. 2014;37:249-64. 


\section{Applying Social Science to Assess Public Interaction with Shale Gas}

5. White House, Office of the Press Secretary. Executive order-using behavioral science insights to better serve the American people. 2015 Sep 15 [cited 2016 Apr 12]; Available from: https://www.whitehouse.gov/the-pressoffice/2015/09/15/executive-order-using-behavioral-science-insights-betterserve-american

6. Attari SZ, DeKay ML, Davidson CI, et al. Public perceptions of energy consumption and savings. Proc Natl Acad Sci USA. 2010;107(37):16054-9.

7. Carrico AR, Padgett P, Vandenbergh MP, et al. Costly myths: an analysis of idling beliefs and behavior in personal motor vehicles. Energy Policy. 2009;37(8):2881-8.

8. Carrico AR, Spoden M, Wallston KA, et al. The environmental cost of misinformation: why the recommendation to use warm water for handwashing is problematic. Int J Consumer Stud. 2013;13:433-41.

9. Murphy J, Southwell BG, Parvanta S. Energy knowledge as a predictor of attitudes toward nuclear power. Presentation given at American Association for Public Opinion Research annual conference, May, 2015; Hollywood, Florida.

10. Southwell BG, Murphy JJ, DeWaters JE, et al. Americans' perceived and actual understanding of energy (RTI Press Publication No. RR-0018-1208). Research Triangle Park, NC: RTI Press; 2012.

11. Converse PE. Changing conceptions of public opinion in the political process. Public Opin Q. 1987;51:s12-24.

12. Delli Carpini MX, Keeter S. What Americans know about politics and why it matters. New Haven, CT: Yale University Press; 1997.

13. Boudet $\mathrm{H}$, Clarke $\mathrm{C}$, Bugden D, et al. "Fracking" controversy and communication: using national survey data to understand public perceptions of hydraulic fracturing. Energy Policy. 2014;65:57-67.

14. Rao V. Shale gas: the promise and the peril (RTI Press Publication No. BK-00091206). Research Triangle Park, NC: RTI Press; 2012.

15. Theodori GL, Luloff AE, Willits FK, et al. Hydraulic fracturing and the management, disposal, and reuse of frac flowback waters: views from the public in the Marcellus Shale. Energy Res Soc Sci. 2014;2:66-74.

16. Raimi KT, Leary MR. Belief superiority in the environmental domain: Attitude extremity and reactions to fracking. J Environ Psychol. 2014;40:76-85.

17. Rabe BG, Borick C. Conventional politics for unconventional drilling? Lessons from Pennsylvania's early move into fracking policy development. Rev Policy Res. 2013;30(3):321-40

18. Davis C, Fisk JM. Energy abundance or environmental worries? analyzing public support for fracking in the United States. Rev Policy Res. 2014;31:1-16.

19. Truelove HB. Energy source perceptions and policy support: image associations, emotional evaluations, and cognitive beliefs. Energy Policy. 2012;45:478-89.

20. Krupnick A, Siikamaki J. Would you pay to reduce risks from shale gas development? Resources Mag. 2014;185:38-43.

21. Israel AL, Wong-Parodi G, Webler T, et al. Eliciting public concerns about an emerging energy technology: the case of unconventional shale gas development in the United States. Energy Res Soc Sci. 2015;8:139-50.

22. Craik KJW. The nature of explanation. Cambridge, UK: Cambridge University Press; 1943.

23. Hwang Y, Southwell BG. Science TV news exposure predicts science beliefs: real world effects among a national sample. Commun Res. 2009;36(5):724-42.

24. Johnson-Laird PN. Mental models. Cambridge, UK: Cambridge University Press; 1983.

25. Jones NA, Ross H, Lynam T, et al. Mental models: an interdisciplinary synthesis of theory and methods. Ecol Soc. 2011;16(1):46.

26. Cacciatore MA, Scheufele DA, Shaw BR. Labeling renewable energies: how the language surrounding biofuels can influence its public acceptance. Energy Policy. 2012;51:673-82.

27. Kriesky J, Goldstein BD, Zell K, et al. Differing opinions about natural gas drilling in two adjacent counties with different levels of drilling activity. Energy Policy. 2013;58:228-36.

28. Clarke CE, Hart PS, Schuldt JP, et al. Public opinion on energy development: the interplay of issue framing, top-of-mind associations, and political ideology. Energy Policy. 2015;81:131-40.

29. Southwell BG, Reynolds BJ, Fowlie K. Communication, media relations and infectious disease surveillance. In: M'ikanatha N, de Valk H, Lynfield R, Van Benden C, editors. Infectious disease surveillance. 2nd ed. Oxford, UK: Wiley; 2013. p. 607-17.
30. Holloway MD, Rudd O. Fracking: the operations and environmental consequences of hydraulic fracturing. Hoboken, NJ: Wiley; 2013.

31. Evensen D, Clarke C, Stedman R. A New York or Pennsylvania state of mind: social representations of gas development in the Marcellus Shale. J Environ Stud Sci. 2014;4:65-77.

32. Burger J, Nakata K, Liang L, et al. Effect of providing information on students' knowledge and concerns about hydraulic fracking. J Toxicol Env Heal A. 2015;78(9):595-601

33. Mazur A. How did the fracking controversy emerge in the period 2010-2012? Public Underst Sci. 2016;25(2):207-2.

34. Shen FY, Ahern L, Baker M. Stories that count: influence of news narratives on issue attitudes. J Mass Commun Q. 2014;91(1):98-117.

35. Hess DJ. To tell the truth: on scientific counterpublics. Public Underst Sci. 2011;20(5):627-41.

36. Slovic P. Perceived risk, trust, and democracy: A systems perspective. Radiat Sci Soc Decision Making. 1994(15):77-93.

37. Renn O, Levine D. Credibility and trust in risk communication. In: Kasperson RE, Stallen PJM, editors. Communicating risks to the public Dordrecht, Germany: Kluwer; 1991. p. 175-218.

38. Balliet D, Van Lange PA. Trust, conflict, and cooperation: a meta-analysis. Psychol Bull. 2013;139(5):1090-112.

39. North DW, Stern PC, Webler T, et al. Public and stakeholder participation for managing and reducing the risks of shale gas development. Environ Sci Technol. 2014;48(15):8388-96.

40. Powers M, Saberi P, Pepino R, et al. Popular epidemiology and "fracking": citizens' concerns regarding the economic, environmental, health and social impacts of unconventional natural gas drilling operations. J Commun Health. 2015;40(3):534-41.

\section{About the Authors}

Matthew M. Strobl, MA, is the director of RTI International's Responsible Resource Development initiative.

Brian G. Southwell, PhD, directs the Science in the Public Sphere Program in the Center for Communication Science at RTI. He also teaches at Duke University and the University of North Carolina at Chapel Hill.

Jason S. Norman, PhD, is head of RTI's Responsible Resource Development initiative. Dr. Norman also leads RTI's corporate-level strategic planning for natural gas energy research.

Lauren A. McCormack, PhD, created and directs RTI's Center for Communication Science. Dr. McCormack is also adjunct associate professor at the Gillings School of Global Public Health at the University of North Carolina at Chapel Hill.

Paul Pulliam, BA, directs RTI's Center for Health Research. He also serves as director of RTI's Chicago office.

\section{Acknowledgments}

Katelyn McDaniel and Brian Blackmon contributed to this research brief.

RTI Press Research Briefs and Policy Briefs are scholarly essays on policy, methods, or other topics relevant to RTI areas of research or technical focus.

RTI International, 3040 East Cornwallis Road, PO Box 12194 Research Triangle Park, NC 27709-2194 USA

$+1.919 .541 .6000 \quad$ rtipress@rti.org www.rti.org

(c)2016 RTI International. All rights reserved. Credit must be provided to the author and source of the publication when the content is quoted. No part of this publication may be reproduced in any form by any electronic or mechanical means without permission in writing from the publisher. RTI International is a registered trademark and a trade name of Research Triangle Institute.

RTI Press publication RB-0013-1607 www.rti.org/rtipress 